\title{
Information gathering through alliances
}

Citation for published version (APA):

Letterie, W., Hagedoorn, J., van Kranenburg, H., \& Palm, F. (2008). Information gathering through alliances. Journal of Economic Behavior \& Organization, 66(2), 176-194. https://doi.org/10.1016/j.jebo.2006.05.003

Document status and date:

Published: 01/05/2008

DOI:

10.1016/j.jebo.2006.05.003

Document Version:

Publisher's PDF, also known as Version of record

\section{Please check the document version of this publication:}

- A submitted manuscript is the version of the article upon submission and before peer-review. There can be important differences between the submitted version and the official published version of record.

People interested in the research are advised to contact the author for the final version of the publication, or visit the DOI to the publisher's website.

- The final author version and the galley proof are versions of the publication after peer review.

- The final published version features the final layout of the paper including the volume, issue and page numbers.

Link to publication

\footnotetext{
General rights rights.

- You may freely distribute the URL identifying the publication in the public portal. please follow below link for the End User Agreement:

www.umlib.nl/taverne-license

Take down policy

If you believe that this document breaches copyright please contact us at:

repository@maastrichtuniversity.nl

providing details and we will investigate your claim.
}

Copyright and moral rights for the publications made accessible in the public portal are retained by the authors and/or other copyright owners and it is a condition of accessing publications that users recognise and abide by the legal requirements associated with these

- Users may download and print one copy of any publication from the public portal for the purpose of private study or research.

- You may not further distribute the material or use it for any profit-making activity or commercial gain

If the publication is distributed under the terms of Article $25 \mathrm{fa}$ of the Dutch Copyright Act, indicated by the "Taverne" license above, 


\title{
Information gathering through alliances ${ }^{\text {is }}$
}

\author{
Wilko Letterie $^{\mathrm{a}, *}$, John Hagedoorn ${ }^{\mathrm{a}}$, \\ Hans van Kranenburg ${ }^{b}$, Franz Palm ${ }^{\mathrm{c}}$ \\ a Department of Organization and Strategy, Faculty of Economics and Business Administration, \\ Maastricht University, P.O. Box 616, 6200 MD Maastricht, The Netherlands \\ ${ }^{\mathrm{b}}$ Nijmegen School of Management, Radboud University Nijmegen, P.O. Box 9108, \\ 6500 HK Nijmegen, The Netherlands \\ ${ }^{c}$ Department of Quantitative Economics, Faculty of Economics and Business Administration, \\ Maastricht University, P.O. Box 616, 6200 MD Maastricht, The Netherlands
}

Received 26 April 2004; accepted 15 May 2006

Available online 2 January 2007

\begin{abstract}
The effect of a firm's uncertainty regarding technological development on the formation of alliances is examined, and it is shown that this uncertainty is positively related to the number of alliances. However, higher uncertainty also makes the firm less likely to ally with others if the collected information is redundant. The higher the similarity between the technological regimes of potential alliance partners, the lower the incentive to ally. Also direct ties are preferred to indirect ones if uncertainty is high since direct ties yield more accurate information than indirect ties.
\end{abstract}

(C) 2006 Elsevier B.V. All rights reserved.

JEL classification: D83; L10; L20

Keywords: Technology alliances; Bayesian learning; Redundant information; Direct and indirect ties; Social and economic networks

\section{Introduction}

In this paper we will consider some theoretical issues regarding the formation of optimal networks through inter-firm alliances from the perspective of an individual company. These inter-

\footnotetext{
is An earlier version of this paper was presented at the MERIT workshop on "Strategic Management, Innovation and Econometrics".

* Corresponding author. Tel.: +31 43 3883645; fax: +31 433884893.

E-mail address: W.Letterie@os.unimaas.nl (W. Letterie).
} 
firm alliances are defined as collaborative agreements between independent companies. We will discuss technology alliances where companies share $R \& D$ and other innovative activities through a range of different collaborative agreements (Hagedoorn and Duysters, 2002). Given the context of these alliances, the main purpose of these collaborative activities is to learn about a particular new technology and to reduce the uncertainty surrounding this new technology.

In this paper we address three topics. The first issue concerns how many alliances a firm will form in order to counter uncertainty. We determine the optimal number of alliances for a particular firm (i.e., the focal firm) when each alliance yields an observation on an uncertain technology or competence, using a Bayesian learning framework (cf. Raiffa and Schlaifer, 1961; DeGroot, 1970). ${ }^{1}$ We find that a higher degree of technological uncertainty necessitates a higher number of alliances. Furthermore, we assume that contacts or ties are partly redundant. In that case, technological information obtained from various sources is, to some extent, similar. In other words, the firms that may potentially ally with the focal firm share a common technological regime (cf. Nelson and Winter, 1977; Dosi, 1982). We study how this technological commonality affects the incentive to form alliances, and we find that a higher degree of commonality reduces the incentive to form alliances.

Second, according to the standard efficiency approach in network analysis (Burt, 1992a,b) it is the number of non-redundant contacts that counts. Companies should limit getting involved with networks where contacts are duplicated. We consider how uncertainty affects the incentive to form either redundant or non-redundant ties. We argue that non-redundant ties yield better information to the firm, though they might be costlier to obtain. In fact, firms that already belong to the network in which a firm participates are usually less costly allies to develop because trust between the members facilitates further alliances (Gulati, 1995b; Nooteboom et al., 1997; Saxton, 1997). The cost of searching for new alliances within the existing network is lower as well (Gomes-Casseres, 1996; Gulati, 1995a; Uzzi, 1997). However, the disadvantage of such ties is that members of an existing network progressively become less attractive candidates to form an alliance with because the information they yield is similar. We show that under higher uncertainty the choice for redundant contacts becomes less likely.

Thirdly, standard network theory argues that 'weak ties' or 'bridge ties' are beneficial in transmitting information from one group of social players to another (Granovetter, 1973; Burt, 1992a,b). Hence, these ties allow a firm to obtain information from a source to which it is not connected directly. The main argument is that firms should aim at forming efficient networks by means of a limited number of direct ties that act as bridges to indirectly connected companies. The assumption here is that direct ties may be substituted for indirect ties. However, the extent to which this is possible may be limited if the merits of direct and indirect ties differ. In particular Ahuja (2000) argues that indirect ties yield only information that is easily communicated. This information can provide only a rather noisy signal of the knowledge present at the indirect link. Direct ties also allow for transmission of tacit and non-codifiable information. Hence, direct ties provide a more accurate signal of the competences available at the direct link. We show, in line with the 'closure' argument by Coleman (1988), that under higher uncertainty the choice for direct contacts becomes more likely in order to improve the communication between the ties.

The paper is structured as follows. In the first section we provide a general outline of the optimisation problem of a firm. In the second section, we investigate under which conditions it

\footnotetext{
${ }^{1}$ The results of these models have been interpreted in the context of alliance formation by Mody (1993) who argues that firms reduce uncertainty by learning through alliances: during each period an alliance exists, an experiment is conducted that yields an observation on the desirability of breaking up, continuing or merging.
} 
becomes more important to form non-redundant ties. In the third section, we discuss the conditions determining when information obtained from indirect ties is dominated by information from direct ties. We draw conclusions and provide directions for future research in the final section.

\section{A Bayesian model of information collection through forming alliances}

This section presents an outline of the optimisation problem from the perspective of the management of a single, representative firm that is interested in information gathering about product or process innovation through alliances (see also Arora and Gambardella, 1994). The basic idea behind the model is that a firm is uncertain about the future direction in which important elements of its technology will develop. ${ }^{2}$ To reduce this uncertainty surrounding technological innovation, the firm can form alliances with other firms to acquire useful information. In the following we adopt a Bayesian two-stage learning model as developed by, among others, Raiffa and Schlaifer (1961) and DeGroot (1970). ${ }^{3}$ In the first stage, the firm decides on the number of its alliances. In the second stage, it decides about the direction of the technology it implements. To develop some notation, consider a firm that is uncertain about important aspects of its future technology or its main competences. Suppose that the desired future direction of the firm's technology is reflected by a parameter $T$ of which the value is unknown and outside the control of the firm. The uncertainty about the value of $T$ is represented by a probability density function (pdf). The technological direction ultimately chosen by the firm is given by the decision parameter $d$. The firm has some prior expectations about the variable $T$, which are derived from information already available. This means that the firm has some notion of the expected direction and degree of uncertainty surrounding technological developments. We formalize this idea by assuming that before the firm forms any alliance, the prior distribution of $T$ is normal with mean $\mu$ and variance $\sigma_{T}^{2}$ :

$$
T \sim N\left(\mu, \sigma_{T}^{2}\right)
$$

It is costly to choose a technology deviating from the desired one. Hence, the firm incurs a cost if the direction $d$ does not match the desired direction given by $T$. In this study the costs when choosing direction $d$ are given by 4

$$
C(T, d)=a|T-d|, \quad a>0 .
$$

The idea is that the costs are influenced by the extent to which the direction $d$ chosen by the firm fits with the desired technology represented by the variable $T$. The firm minimizes the expected value of $C(T, d)$ by choosing $d^{\text {opt }}$. This means that $d^{\text {opt }}$ is determined by

$$
\min _{d} \underset{T}{E} C(T, d)
$$

where $E$ denotes that expectations are taken with respect to $T$. If $T$ is known with certainty, it is obviously optimal to select $d=T$. However, $T$ is assumed to be unknown, and the uncertainty about its value is represented by a prior probability distribution function as given by Eq. (1).

The firm does not need to fix $d$ immediately. In fact, it has the opportunity to collect information about the properties of $T$ by forming alliances with other firms. Before we develop the model in

\footnotetext{
${ }^{2}$ Instead of using the concept of technology one could also think of a firm's core competences.

${ }^{3}$ Parts of this section are closely related to Cukierman (1980). In our model the parameter $n$ reflects the number of alliances the firm selects. Cukierman interprets $n$ as the optimal number of periods a firm may collect observations of $x$.

4 A quadratic cost function could be used as an alternative.
} 
detail, we will first provide an informal example of the information acquisition process by means of alliance formation. Consider the period from the mid-1970s to the 1980s, when traditional pharmaceutical companies such as Johnson \& Johnson, Smithkline Beecham, and Hoffmann-La Roche entered into R\&D alliances, mostly R\&D contracts, with a group of new biotechnology companies that all specialized in revolutionary new technologies based on genetic engineering and cell fusion that could potentially transform completely the way in which pharmaceutical products were developed and which were unrelated to the traditional technologies pharmaceutical firms mastered. ${ }^{5}$ Such developments caused a high level of uncertainty regarding future technologies or competences for the large pharmaceutical firms, as represented by $T$ in our model. Existing pharmaceutical technology was based on organic chemistry and random mass screening of chemical compounds, whereas biotechnology, developed by this group of new companies, shared a body of knowledge based on immunology, molecular biology, and DNA technology. In search for these new technologies Johnson \& Johnson teamed up with Enzo-Biochem, Chiron, Amgen, Integrated-Genetics, International Clinical Laboratories, Immunomedics, and British Biotech. Smithkline Beecham entered into R\&D alliances with Cetus, Immunex, British Biotech, Applied Immunesciences, Cambridge Bioscience, Reckitt \& Colman, and Biogen. Hoffmann-La Roche formed alliances with Genentec, Damon Biotech, Cetus, Genzyme, Xoma, Biodor, and Synergen.

We consider the following situation: each time the firm sets up an alliance with another firm, it receives information by observing the realization of a random variable $x_{i}$. We assume that $x_{i}=y_{i}+\varepsilon$, which means that each time information is acquired, it is based on two different independently distributed components: an idiosyncratic component $y_{i}$ and a common component $\varepsilon$. These two components can be motivated as follows. First, since each potential alliance partner is different due to firm specific resources (Barney, 1991, 2001; Eisenhardt and Schoonhoven, 1996; Madhok and Tallman, 1998), each alliance yields some unique information represented here by $y_{i}$. For instance, the small biotechnology firms mentioned previously all specialized in a few projects and product applications because of a limited amount of resources. Therefore, they all build firm specific knowledge bases (Roijakkers et al., 2005), for example Chiron initially concentrated on genetically engineered vaccines for hepatitis, Enzo-Biochem on gene and immune regulation and gene editing, Immunomedics on monoclonal anti-body based products, Cetus on multiplying DNA sequences, Biogen on recombinant alpha interferon, Genzyme on various immune diseases, and Xoma on cell expression technology for the production of recombinant proteins. Given the different knowledge bases of different partners, the first information component $y_{i}$ generated by an alliance does not resemble information obtained from other alliances. In other words, this means in statistical terms that this piece of information is uncorrelated with that obtained from other potential alliance partners. In fact, the first variable $y_{i}$ varies with each alliance formed by the firm. It is independently and identically normally distributed with $y \sim N\left(E_{y}, \sigma_{y}^{2}\right)$.

Second, the potential partners belong to a group of similar firms in the sense that they do share a common base of knowledge, as found for instance in common technological regimes (Dosi, 1982; Nelson and Winter, 1977). In our setup the random variable $\varepsilon$ accounts for the common base of knowledge. The implication of a common technological knowledge base is that information derived from different firms that are members of a certain industry will also show some overlap. For instance, Powell et al. (1996) suggest the presence of a certain degree of overlap in the academic culture and scientific and technological knowledge base of the new biotechnology companies in the 1970s and 1980s. Hence, to some extent the knowledge sets

5 This information is drawn from the MERIT-CATI database on inter-firm R\&D alliances. 
of these biotechnology firms showed some degree of similarity because they were all based on immunology, molecular biology and DNA technology. To capture the presence of this kind of overlap, we assume that alliances also yield a second information component that is identical across partnerships. Hence, all observations $x_{i}$ share a common component given by the second stochastic term $\varepsilon$, which does not change with the alliances formed. It has a normal distribution $\varepsilon \sim N\left(E_{\varepsilon}, \sigma_{\varepsilon}^{2}\right)^{6}$

Next, we assume that the expected value of $x_{i}$ which is given by $E_{x}=E_{y}+E_{\varepsilon}$, equals $E_{x}=T$. $^{7}$ Hence, the desired future direction of the technology $T$ is the mean of the normally distributed variable $x$. As a consequence, if the firm obtains an observation $x$, this yields some information about $T$. Note that the firm can only observe the sum of $y_{i}$ and $\varepsilon$. It does not identify these two terms separately. The variances of the two components of $x_{i}$ (i.e., $y_{i}$ and $\varepsilon$ ) are assumed to be given and known. The total variance of $x_{i}$ is given by $\sigma_{y}^{2}+\sigma_{\varepsilon}^{2}$. The lower this variance, the higher the precision will be of the firm's estimate of the future desired technology $T$. The variances $\sigma_{\varepsilon}^{2}$ and $\sigma_{y}^{2}$ are present for several reasons. First, the partner firm may lack the ability or the incentives to transmit its information without ambiguity. For instance, knowledge may be tacit and hence inherently difficult to communicate to individuals not familiar with the organization in which the information is embedded (Howells, 1996). Furthermore, a firm may want to protect crucial elements of its knowledge base and only release parts of it (Arora, 1995; Poppo and Zenger, 2002; Ring, 2002). ${ }^{8}$ Second, information obtained from a partner may lack clarity due to an insufficient learning capability of the firm that decides about the optimal number of partners. A firm needs a certain absorptive capacity to be able to evaluate and utilize information properly (Cohen and Levinthal, 1990). Third, the partner firm may be uncertain itself about the precise value of the future technology. Hence, the total variance $\sigma_{y}^{2}+\sigma_{\varepsilon}^{2}$ may reflect its own degree of uncertainty regarding the value of $T$.

The above three concerns may be different for the two variables $\varepsilon$ and $y$. Furthermore, $\sigma_{y}^{2}$ and $\sigma_{\varepsilon}^{2}$ may differ for the following reason. Consider a large pharmaceutical company in the 1980s that wishes to obtain competences in biotechnology. As explained above, new biotechnology knowledge was largely developed within a group of new companies that shared a general basic knowledge developed from core technologies such as DNA synthesising and sequencing, and cell fusion methodologies for producing hybridomas (see also Powell et al., 1996, p. 122). Such core technologies refer to the type of knowledge we consider to be common among the potential partners, which is formalised by the variable $\varepsilon$ in our model. However, for the actual development of new projects and specific technologies, nearly all of these small biotechnology firms could specialize only in particular sub-disciplines and concentrate on one or a few research projects and product applications, thereby developing firm specific knowledge that is captured by the

\footnotetext{
${ }^{6}$ In our model information obtained by an alliance is based on some knowledge that is shared (common) among the potential partners. The notion of 'common' only refers to the part of information that is similar among the potential partners of the firm. It is not information that is publicly available to firms outside the set of potential partner firms. Hence, to the firm that determines its optimal number of partners this information is new in our model. This assumption can be relaxed. We will discuss this matter in the final paragraph of this section, where we argue that our findings still hold if the focal firm has already obtained information from prior alliances with the same common knowledge component.

7 This assumption does not affect our main findings. One may also assume that $E_{y}=T(0)$ and $E_{\varepsilon}=0(T)$. It is important that the sum of $E_{y}$ and $E_{\varepsilon}$, which determine $E_{x}$, equals $T$ since the mean of the sum of normally distributed variables is the sum of the respective means.

${ }^{8}$ In our model we assume that strategic motives affect the variance of the signal provided by the partner, but not the expected value. The precise modelling of strategic manipulation of information applying game theoretic models of asymmetric information is beyond the scope of this study.
} 
random term $y_{i}$ (Roijakkers et al., 2005). In this case, for the large pharmaceutical company the observations $x_{i}$ only partly overlap with each other, since these potential partners (i.e., the small biotechnology firms) are forced to specialize in particular subfields. Hence, in this example the variance $\sigma_{y}^{2}$ is likely to be substantial compared with the variance $\sigma_{\varepsilon}^{2}$.

Consider now a small biotechnology firm in the same era that lacks competences in areas such as obtaining financial resources, drug testing, obtaining legal permission to sell a particular drug, manufacturing or marketing. In this case the parameter $T$ and its statistical properties reflect the biotechnology firm's uncertainty on how to commercialize its product for instance. Such competences are available in large pharmaceutical firms (Rothaermel and Deeds, 2004). However, with respect to these competences, it is likely that certain common standards have developed among the large companies since the industry was relatively mature at that time (Rothaermel, 2001). Hence, the potential partners for a small biotechnology firm that possess such competences were likely to provide similar information. In this example the variance of the common knowledge component $\sigma_{\varepsilon}^{2}$ is likely to be large compared with the variance $\sigma_{y}^{2}$ in terms of our model. Then information on the desired competence as given by $T$ is largely determined by a common understanding among the potential partner firms and not by idiosyncratic knowledge.

If the firm obtains various observations by forming alliances, they contain partly similar information. The relative size of $\sigma_{y}^{2}$ and $\sigma_{\varepsilon}^{2}$ determines the amount of overlap between observations from different partners. Intuitively, this can be understood as follows. Suppose that the variance of the common component $\varepsilon$ becomes larger relative to $\sigma_{y}^{2}$. This implies that it becomes more likely that the value of $y$ is relatively small compared to the size of $\varepsilon$. In this case the observations $x_{i}$ are largely determined by the larger (in absolute terms) common component $\varepsilon$. More formally, this feature is reflected in statistical terms by the degree of correlation of the observations. To see this consider the $n$ by $n$ covariance matrix $\Sigma_{x}^{n}$ of $n$ observations $x_{1}, x_{2}, \ldots, x_{n}$ :

$$
\Sigma_{x}^{n}=\left[\begin{array}{llll}
\sigma_{y}^{2}+\sigma_{\varepsilon}^{2} & \sigma_{\varepsilon}^{2} & \cdot & \sigma_{\varepsilon}^{2} \\
\sigma_{\varepsilon}^{2} & \sigma_{y}^{2}+\sigma_{\varepsilon}^{2} & \cdot & \cdot \\
\cdot & \cdot & \cdot & \sigma_{\varepsilon}^{2} \\
\sigma_{\varepsilon}^{2} & \cdot & \sigma_{\varepsilon}^{2} & \sigma_{y}^{2}+\sigma_{\varepsilon}^{2}
\end{array}\right] .
$$

The correlation coefficient of two different observations $x_{i}$ and $x_{j}$ equals $\rho_{i, j}=\sigma_{\varepsilon}^{2} /\left(\sigma_{y}^{2}+\sigma_{\varepsilon}^{2}\right)>$ 0 . Since this expression does not depend on $i$ and $j$, we drop subscripts and refer to the correlation coefficient $\rho \equiv \rho_{i, j}$ in the rest of this paper. It appears that the correlation between $x_{i}$ and $x_{j}$ increases with the variance $\sigma_{\varepsilon}^{2}$ and decreases with the variance $\sigma_{y}^{2}$. Hence, if the variance of $\varepsilon$ is high relative to that of $y$, the information carried by the variable $x$ will largely be influenced by the informational content of $\varepsilon$. Therefore, if the variance $\sigma_{\varepsilon}^{2}$ is high compared to the variance $\sigma_{y}^{2}$, the two observations $x_{i}$ and $x_{j}$ will both be highly affected by the presence of similar information among the potential partner firms and much less by the alliance specific information (i.e., $y_{i}$ ), implying a high coefficient of correlation. Hence, in our model it is not the absolute size of $\sigma_{\varepsilon}^{2}$ that determines the strength of the technological regime within the group of potential alliance partners. It is the relative size of $\sigma_{\varepsilon}^{2}$ with respect to $\sigma_{y}^{2}$. 9

\footnotetext{
${ }^{9}$ One could also argue that a strong technological regime reflects a situation in a mature industry where for instance firms have converged to similar competences that they master with high precision. However, for an industry outsider that wants access to such capabilities by forming alliances, information obtained from such sources may, as explained before, be surrounded with considerable uncertainty due to ambiguity in the information transmission or a limited absorptive
} 
Information becomes available at a cost, which represents the cost of setting up an alliance and the cost of collecting and evaluating the information. The total cost per observation of $x$ is given by $c$. If the firm decides to observe $n$ values of the variable $x$ before it chooses its direction $d$, the firm uses the acquired information to update its knowledge concerning the variable $T$ using Bayesian learning. ${ }^{10}$ This knowledge is given by the posterior distribution of $T$ that incorporates all information that is contained in the observations $x_{1}, x_{2}, \ldots, x_{n}$. The parameters of the prior pdf (1) are assumed to be given and known. The variance of the random variable $x$ in (4) is also assumed to be given and known. ${ }^{11}$

The optimal number of information-gathering alliances before the firm determines its optimal direction $d^{\text {opt }}$ can be determined as follows. The firm chooses $n$ to minimize the expected value of the cost function $C(T, d)$ presented in equation (2) given the posterior beliefs concerning $T$ and the cost of collecting information given by $n c$. Hence, $n$ is found by

$$
C=\min _{n}\left(\min _{d} \underset{T, n}{E} C(T, d)+n c\right) .
$$

The $n$ under the expectations operator in Eq. (6) denotes that $d$ is chosen using the posterior distribution of $T$ after $n$ observations of $x$. The minimized expected cost the firm incurs equals $C$. In order to derive the optimal number of information-gathering alliances, we first need to determine the firm's optimal direction $d^{\text {opt }}$ using Eqs. (2) and (3). We find that

$$
\min _{d} \underset{T, n}{E} C(T, d)=a \min _{d} E|T-d|
$$

The optimal direction $d^{\text {opt }}$ is equal to the median of the distribution of $T$ (DeGroot, 1970, p. 232). Since the posterior distribution of $T$ is normal and therefore symmetrically distributed around its mean, the optimal strategy of the firm is given by $d^{\mathrm{opt}}=\mu_{n}$ (i.e., the expected value of $T$ given its posterior distribution). The minimized value of Eq. (6) is given by (DeGroot, 1970, p. 233)

$$
\min _{d} \underset{T, n}{E} C(T, d)=a \sqrt{\frac{2 \sigma_{n}^{2}}{\pi}} .
$$

It appears that the expected cost the firm incurs depends on the degree of uncertainty remaining after $n$ observations as given by $\sigma_{n}^{2}$. The higher the uncertainty as measured by $\sigma_{n}^{2}$, the higher the cost. Therefore, the firm has an incentive to reduce the uncertainty it faces. Using Eq. (5) the firm's optimisation problem becomes

$$
\min _{n}\left(a \sqrt{\frac{2 \sigma_{n}^{2}}{\pi}}+n c\right) .
$$

capacity. The variance $\sigma_{\varepsilon}^{2}$ it perceives may still be relatively high because of this, even though the partner firm faces little uncertainty regarding its competences.

${ }^{10}$ Note that $n$ refers to the number of alliances the firm selects.

11 This assumption could be dropped easily. When the variance of $x$ is unknown, the uncertainty surrounding its value could be represented by a prior pdf, such as using an inverted gamma pdf (see e.g. Raiffa and Schlaifer, 1961). 
The variance of $T$ given its posterior distribution, which incorporates all information $x_{1}, x_{2}$, $\ldots, x_{n}$, is given by

$$
\sigma_{n}^{2}=\left(\frac{1}{\sigma_{T}^{2}}+\frac{n}{\sigma_{y}^{2}+n \sigma_{\varepsilon}^{2}}\right)^{-1} .
$$

The derivation of this expression is given in the appendix which is available on the JEBO website. Before proceeding with the optimization problem of the firm let us consider two extreme cases. First, consider the situation where each partnership provides some alliance specific information and information that is similar within the group of potential partner firms. Suppose now that the variance of common information is very large: $\sigma_{\varepsilon}^{2}$ approaches infinity. Then the posterior variance $\sigma_{n}^{2}$ equals the variance of the prior distribution $\sigma_{T}^{2}$. This means that in this case, forming alliances does not provide any useful information since the degree of uncertainty faced by the firm remains equal to its prior degree of uncertainty given by $\sigma_{T}^{2}$. The explanation is as follows. The correlation coefficient between two observations $x_{i}$ and $x_{j}$ (i.e., $\rho=\sigma_{\varepsilon}^{2} /\left(\sigma_{y}^{2}+\sigma_{\varepsilon}^{2}\right)$ ) approaches one in this case. This means that two alliances provide exactly the same information. Hence, the maximum number of alliances that possibly provides relevant information is one. However, an observation $x_{i}$ is drawn out of a distribution with a variance that approaches infinity $\left(\sigma_{x}^{2}=\sigma_{y}^{2}+\sigma_{\varepsilon}^{2}\right)$. Therefore the estimate of $T$ based on observation $x_{i}$ is very inaccurate and does not lead to a reduction of uncertainty as measured by $\sigma_{n}^{2}$. Hence, it is optimal to build no alliances.

Second, suppose now that the technological regime within the group of potential partner firms is strong. This means that information derived from an alliance is compelled by the technological regime and not by alliance specific information (i.e., $y_{i}$ ). In terms of our model, this happens when $\sigma_{y}^{2}$ is small relative to $\sigma_{\varepsilon}^{2}$, because then, as the correlation coefficient $\rho$ indicates, two observations $x_{i}$ and $x_{j}$, are highly correlated. Consider the extreme case where the variance of the idiosyncratic term is zero (i.e., $\sigma_{y}^{2}=0$ and $\rho=1$ ). This implies that information derived from the alliance is completely based on the shared technological regime. Hence, within the set of potential partners, information about the technology is exactly the same. Therefore one alliance is enough to acquire all information available, and the optimal number of alliances is either zero or one, depending on whether the benefits of an alliance outweigh the cost of establishing a partnership. The posterior variance of $T$ after observing $x$ is equal to $\sigma_{n}^{2}=\left(\left(1 / \sigma_{T}^{2}\right)+\left(1 / \sigma_{\varepsilon}^{2}\right)\right)^{-1}$, which is independent of the number of observations: $n$. If $\sigma_{\varepsilon}^{2}$ approaches zero, then $\sigma_{n}^{2}$ becomes zero as well, and the firm knows the value of $T$ precisely.

Let us now return to the optimization problem faced by the firm. The first and second order conditions for the optimization of equation (5) become

$$
\begin{aligned}
\text { FOC : } & -\frac{1}{2} a \sqrt{\frac{2}{\pi}}\left(\frac{1}{\left(\sigma_{y}^{2} / n\right)+\sigma_{\varepsilon}^{2}}+\frac{1}{\sigma_{T}^{2}}\right)^{-3 / 2}\left(\frac{\sigma_{y}^{2} / n^{2}}{\left(\left(\sigma_{y}^{2} / n\right)+\sigma_{\varepsilon}^{2}\right)^{2}}\right)+c=0, \\
\text { SOC }: & \frac{1}{2} a \sqrt{\frac{2}{\pi}} \frac{\left(1 /\left(\sigma_{y}^{2} / n+\sigma_{\varepsilon}^{2}\right)+1 / \sigma_{T}^{2}\right)^{-3 / 2}}{\left(\sigma_{y}^{2}+n \sigma_{\varepsilon}^{2}\right)^{3}} \\
& \times\left(\frac{3}{2}\left(\frac{1}{\sigma_{y}^{2} / n+\sigma_{\varepsilon}^{2}}+\frac{1}{\sigma_{T}^{2}}\right)^{-1}\left(\frac{\sigma_{y}^{4}}{\sigma_{y}^{2}+n \sigma_{\varepsilon}^{2}}\right)+2 \sigma_{y}^{2} \sigma_{\varepsilon}^{2}\right)>0 .
\end{aligned}
$$


As all components of the SOC are positive, the second order condition for a minimum is always satisfied. The FOC depicted above implicitly identifies the optimal number of alliances. ${ }^{12}$ Unfortunately, it is not possible to derive an explicit expression for the optimal $n$ (taking $n$ as a continuous variable, in practice one will take the integer value of the optimal value for $n$ resulting from the optimisation problem). However, in the appendix we derive a number of comparative static results that we summarize in the following proposition. ${ }^{13}$

Proposition 1. The optimal number of information gathering alliances, denoted by $n$,

\section{- decreases with the cost c of setting up an alliance,}

- increases with the cost attached to making mistakes as measured by the parameter a,

- increases with the degree of uncertainty the firm faces as measured by $\sigma_{T}^{2}$,

- decreases with the variance $\sigma_{\varepsilon}^{2}$ of the common random term $\varepsilon .{ }^{14}$

The proposition indicates that the optimal number of alliances decreases with the cost (i.e., $c$ ) of setting up an alliance. ${ }^{15}$ If the cost associated with making mistakes increases, as measured by the parameter $a$, the optimal value of $n$ also increases. It can be seen straightforwardly that the higher the initial uncertainty as measured by the variance $\sigma_{T}^{2}$, the larger the number of alliances the firm is willing to form. Hence, there exists a relationship between a firm's incentive to collect information through alliances and the degree of uncertainty it faces. In classical social network theory this is referred to as 'gregariousness' (Erbe, 1962) where uncertainty is countered by increasing the number of contacts (i.e., alliances) that will lead to increasing flows of information. Some recent empirical studies found that under conditions of increasing uncertainty, companies use large numbers of alliances to improve their learning and information collection capability. These empirical findings refer to a variety of high-tech industries such as semiconductors (GomesCasseres, 1996), data processing (Hagedoorn and Duysters, 2002) and biotechnology (Powell et al., 1996; Walker et al., 1997).

The fourth result should be interpreted as follows. We noted before that $\rho=\sigma_{\varepsilon}^{2} /\left(\sigma_{y}^{2}+\sigma_{\varepsilon}^{2}\right)$. Hence, the correlation between $x_{i}$ and $x_{j}$ increases with the variance $\sigma_{\varepsilon}^{2}$. This means that if the informational content of the various observations gathered by forming alliances becomes more similar, the optimal number of alliances decreases. In other words, the firm is less likely to form a multitude of alliances if these alliances yield more similar information and therefore have a higher degree of redundancy. Hence, in case the partner firms share a common technological regime the incentive to form alliances is reduced. ${ }^{16}$ This line of thought refers to the current efficiency approach in network analysis (Burt, 1992a,b) which stresses that the size of a specific

\footnotetext{
12 Note that if we substitute $\sigma_{\varepsilon}^{2}=0$ in the FOC depicted in Eq. (8) and solve for $n$, we obtain the well-known optimisation problem as studied by Raiffa and Schlaifer (1961), DeGroot (1970) and Cukierman (1980). The SOC guarantees optimality of this case as well.

13 Our results would not be affected if instead of assuming that an observation $x_{i}$ is the sum of two stochastic variables, an idiosyncratic component $y_{i}$ and a common component $\varepsilon$, we assume that $x_{i}$ is normally distributed with mean $T$ and variance $\sigma_{x}^{2}$ and that two variables $x_{i}$ and $x_{j}(i \neq j)$ have a covariance equal to $\rho \sigma_{x}^{2}$ where $\rho$ is the positive correlation coefficient between $x_{i}$ and $x_{j}$. Note that $\rho=\operatorname{cov}\left(x_{i}, x_{j}\right) / \sigma_{x}^{2}$. In the appendix we consider this case.

14 In line with our previous footnote we could also rephrase this statement by saying that the optimal number of alliances decreases if the correlation coefficient $\rho$ of the variables $x_{i}$ and $x_{j}(i \neq j)$ increases.

15 While the first result of Proposition 1 is in line with Mody's finding, we do not account for uncertainty to increase the possibility of opportunistic behaviour and hence the perceived costs of an alliance, which tend to reduce alliance activity. 16 The correlation coefficient of the signals obtained from partners that possess competences in technologies that are in an early stage is likely to be low. Then the incentive to form alliances is high. This is illustrated by the high number of alliances
} 
network of alliances of a company is not that important for the adequate transfer of information. What really counts is the number of non-redundant contacts, because it is assumed that redundant contacts carry the same information. By definition, dense networks involve a considerable degree of interaction between companies, and many of these interactions are expected to be redundant and inefficient. In standard network analysis terminology this implies that the structural equivalence in a network (the degree of interaction with the same group of companies) and the cohesion in networks (the connectivity of companies) should be limited to benefit from its contacts (see also Knoke and Kuklinski, 1982). Therefore, a company should avoid duplication of contacts, it should create well-informed and selective linkages that generate so-called structural autonomy and that exercise control over rewarding opportunities (i.e., the structural equivalence in its network should be small). According to for example Burt (1992a), the lower the number of structural equivalent partners that a firm faces, the more effective a firm's portfolio of alliances is (see also Lorrain and White, 1971). Section 2 provides a more detailed illustration of this issue.

Thus far we have assumed in our model that the information acquired by the alliances does not correlate with knowledge the focal firm already has. This assumption can be relaxed as follows. We can assume that the focal firm has already established $m$ alliances previously yielding observations $x_{i}=y_{i}+\varepsilon$ with the same properties as we adopted above. Using this information the firm will update its beliefs concerning $T$ by forming a posterior distribution using the $m$ observations as we have depicted in this section and the appendix. Next the firm may decide upon additional alliances, providing observations $x_{i}=y_{i}+\varepsilon$, which are correlated with the $m$ previous ones. This decision will be based on the new posterior distribution of $T$ that incorporates the information of $m$ observations obtained previously and the new observations. Cukierman (1980, p. 469) observes that using such a sequential decision procedure instead does not affect the optimal number of observations $n .{ }^{17}$ If we adjust our model along these lines, we would obtain results consistent with Proposition 1. For instance, if new observations are more correlated with the $m$ previous ones or if uncertainty decreases, the optimal number of additional observations decreases.

\section{When does non-redundancy become important?}

In the above, we considered the case where all observations have part of the information in common as these observations are correlated. In other words they share a common knowledge base. Now, we introduce a simple framework in which the firm may choose to acquire observations that are either correlated or uncorrelated with previous ones. Hence, we discuss under which conditions firms should try to avoid duplication of information through alliances.

Suppose now that two networks of firms exist, which we denote by networks A and B. Observations obtained from alliances with companies that belong to network $\mathrm{A}$ are given by $x_{i}=y_{i}+\varepsilon_{\mathrm{A}}$. As in the previous section the variable $y_{i}$ varies with each alliance formed by the firm and is independent across different firms. It is identically normally distributed with $y \sim N\left(E_{y}, \sigma_{y}^{2}\right)$ with variance assumed to be given and known. The observations $x_{i}$ share a common term $\varepsilon_{\mathrm{A}}$, which does not change with the alliances formed within network A. It has a normal distribution $\varepsilon_{\mathrm{A}} \sim N\left(E_{\varepsilon}, \sigma_{\varepsilon}^{2}\right)$

with biotechnology firms established by large pharmaceutical companies as discussed before (see also Roijakkers et al., 2005). The correlation coefficient is probably higher if observations stem from firms operating in industries with mature technologies. Then the added value of new alliances with firms from the same group is lower, which is consistent with the observation that companies in industries like heavy electrical equipment, basic chemicals and food and beverages, which are relatively mature and technologically less turbulent, establish few partnerships (Hagedoorn, 1995).

17 In fact, we adopt a sequential decision procedure in the next section. 
with variance assumed to be given and known. This assumption implies that observations within a certain network are correlated and hence show some overlap. Support for this assumption is found in Gomes-Casseres (1996) and Uzzi (1997) who found that within a network of interacting firms, knowledge across the constituents will become similar. To keep the model tractable we do not formally derive how information becomes similar within a network. Network B is very similar in the sense that observations provided by firms that make up the group are given by $x_{i}=y_{i}+\varepsilon_{\mathrm{B}}$ and the variable $y_{i}$ varies independently with each alliance formed by the firm. For the sake of convenience we assume it is also identically normally distributed with $y \sim N\left(E_{y}, \sigma_{y}^{2}\right)$. The common component of the observations $x_{i}$ in network $\mathrm{B}$ is $\varepsilon_{\mathrm{B}}$, which has a normal distribution $N\left(E_{\varepsilon}, \sigma_{\varepsilon}^{2}\right)$ as well to facilitate the discussion. We assume again that $E_{y}+E_{\varepsilon}=T$. The stochastic terms $\varepsilon_{\mathrm{A}}$ and $\varepsilon_{\mathrm{B}}$ are assumed to be independent. Hence, if observations are obtained from firms that belong to different networks, they do not show any overlap. In statistical terms, these observations are not correlated. Furthermore, we presume that the variances of the stochastic terms $\varepsilon_{\mathrm{A}}$ and $\varepsilon_{\mathrm{B}}$ are equal. This assumption could be dropped. In fact the degree of precision of the information available within networks A and B may depend on the size and structure of the networks. However, for convenience and without affecting the main conclusions of our study, we do not consider this possibility.

Suppose now that the firm has already formed an alliance with a firm in network A. ${ }^{18}$ The firm now belongs to network $\mathrm{A}$ and has access to information derived from the technological regime that is present in network A. Information derived from its alliance with a firm in network A is optimally included in its knowledge base by Bayesian learning. The firm we consider and the firms in network A have become similar to some extent in terms of their knowledge bases. In fact, an additional alliance with a firm from network A will yield information that partly overlaps with the information it already possesses (i.e., a new observation is correlated with an observation it already obtained). However, an alliance with a firm from network B will not show any overlap with its knowledge base (i.e., an observation from network B is not correlated with its observation from network A). Hence, our firm may build an alliance with a firm that is similar (from network A) or with a firm that is dissimilar (from network B) in terms of its knowledge base.

Consider now the firm's decision of setting up an alliance with another firm from either networks A or B. Using the result depicted in Eq. (7) the variance of $T$ after two observations from network $\mathrm{A}$ is given by

$$
\sigma_{\mathrm{AA}}^{2}=\left(\frac{1}{\sigma_{T}^{2}}+\frac{2}{\sigma_{y}^{2}+2 \sigma_{\varepsilon}^{2}}\right)^{-1} .
$$

If the firm chooses to cooperate with a firm from network B, the variance of each observation will be equal to $\sigma_{x}^{2}=\sigma_{y}^{2}+\sigma_{\varepsilon}^{2}$. Furthermore, the observations from the two different networks A and $\mathrm{B}$ are independent. Therefore, we find, in line with Section 1, that after two observations the posterior variance of the variable $T$ becomes ${ }^{19}$ :

$$
\sigma_{\mathrm{AB}}^{2}=\left(\frac{1}{\sigma_{T}^{2}}+\frac{2}{\sigma_{y}^{2}+\sigma_{\varepsilon}^{2}}\right)^{-1}
$$

\footnotetext{
18 The results derived in this section still apply if we assume the focal firm has already established $m$ alliances previously with firms from network A.

19 To see this use Eq. (7) and fill in $n=2, \sigma_{\varepsilon}^{2}=0$ and $\sigma_{y}^{2}=\sigma_{y}^{2}+\sigma_{\varepsilon}^{2}$.
} 
The cost of forming an alliance with an additional company from network $\mathrm{A}$ is denoted $c_{\mathrm{A}}$. If the firm chooses a partner from network $\mathrm{B}$ the cost is given by $c_{\mathrm{B}}$. One may argue that the cost $c_{\mathrm{B}}$ is larger than $c_{\mathrm{A}}$. For instance, once alliances have been established within a network, trust between the members may facilitate further alliances as found by Gulati (1995b), Nooteboom et al. (1997) and Saxton (1997). Also, the cost of searching for new useful partners may be lower within the existing network (Gomes-Casseres, 1996; Gulati, 1995a; Uzzi, 1997).

However, as indicated in the above, companies might have an advantage in forming alliances with companies from network B. Let $\sigma_{\mathrm{A}}^{2}$ denote the variance of the predictor of $T$ after one observation of a firm out of network A. The firm will choose a firm from network $B$ if the marginal benefit of adding a network B observation is higher than the marginal benefit from additional information from network $\mathrm{A}$ :

$$
-a\left(\sqrt{\frac{2 \sigma_{\mathrm{AB}}^{2}}{\pi}}-\sqrt{\frac{2 \sigma_{\mathrm{A}}^{2}}{\pi}}\right)-c_{\mathrm{B}}>-a\left(\sqrt{\frac{2 \sigma_{\mathrm{AA}}^{2}}{\pi}}-\sqrt{\frac{2 \sigma_{\mathrm{A}}^{2}}{\pi}}\right)-c_{\mathrm{A}} .
$$

Since $\sigma_{\mathrm{AA}}^{2}>\sigma_{\mathrm{AB}}^{2}$ the inequality of Eq. (11) will hold if the cost of setting up an alliance with a firm from $\mathrm{B}$ is relatively low. Furthermore, if the degree of uncertainty (i.e., $\sigma_{T}^{2}$ ) faced by the firm is larger, Eq. (11) is also more likely to hold, because

$$
\frac{\partial\left(-\sqrt{2 \sigma_{\mathrm{AB}}^{2} / \pi}+\sqrt{2 \sigma_{\mathrm{AA}}^{2} / \pi}\right)}{\partial \sigma_{T}^{2}}>0 .
$$

This leads to our second proposition.

Proposition 2. If the environment faced by the firm is becoming more uncertain, as measured by $\sigma_{T}^{2}$, the firm is likely to avoid duplication of information through alliances within its existing network. ${ }^{20}$

Within the context of our model, assuming higher uncertainty, firms that are members of the existing network (here network A) gradually become less attractive allies because they actually yield similar information. Hence, members of other networks to which the firm has no contacts yet become more appealing candidates to ally with. To illustrate this, a recent empirical study of a very volatile environment by Roijakkers and Hagedoorn (2006) shows that up to the 1980s large pharmaceutical companies allied with biotechnology companies to obtain competences in basic research in the fields of cell fusion and genetic engineering. During the 1980s they gradually changed to forming $R \& D$ alliances with less emphasis on basic research as the main objective of the alliance. In that context, new R\&D partnerships focused more and more on high-risk applied research and new product development and less on the scanning of new technologies. In their comparison of different inter-firm R\&D networks in pharmaceutical biotechnology over a 25year period, Roijakkers and Hagedoorn (2006) also notice that nodal companies, such as Johnson \& Johnson, Smithkline Beecham, and Hoffmann-La Roche, have flexible and changing networks in which they build new R\&D partnerships with a variety of companies. The specific role of many

\footnotetext{
20 This proposition also holds if the correlation coefficient of two observations derived from networks A and B as measured by $\rho_{\mathrm{AB}}$ is positive (rather than zero as in this section) but smaller than the correlation coefficient of two observations obtained from firms in network A (i.e., $\left.\rho_{\mathrm{AA}}\right)$. Using the results we derive in the appendix related to footnote 13 we find that in this case $\sigma_{\mathrm{AA}}^{2}=\left(\left(1 / \sigma_{\mathrm{T}}^{2}\right)+2 /\left(\sigma_{x}^{2}\left(1+\rho_{\mathrm{AA}}\right)\right)\right)^{-1}$ and $\sigma_{\mathrm{AB}}^{2}=\left(\left(1 / \sigma_{\mathrm{T}}^{2}\right)+2 /\left(\sigma_{x}^{2}\left(1+\rho_{\mathrm{AB}}\right)\right)\right)^{-1}$. Hence, if $\rho_{\mathrm{AA}}>\rho_{\mathrm{AB}}$, then $\sigma_{\mathrm{AA}}^{2}>\sigma_{\mathrm{AB}}^{2}$, and all arguments apply again.
} 
specialized biotechnology firms, as it emerged during the early decades of pharma-biotechnology, has changed over time. The network of players in pharmaceutical biotechnology in the second half of the 1990s consists of a very different group of partners, most of them more established companies with a greater variety of technological skills than those found in the group of dedicated biotechnology companies that were the alliance candidates of the large pharmaceutical firms in the 1970 s and 1980s.

\section{When do direct ties dominate indirect ties?}

In this section we present a model to determine when a direct tie, that carrying information directly from another company, is preferred to an indirect tie where information is based on transfer from a company in a network through a single bridge tie. Standard social network theory assumes that it is beneficial for companies to access existing information through a limited number of direct contacts while avoiding direct links to dense inefficient networks. This line of reasoning is based on classical arguments such as, for instance, found in Granovetter's 'weak ties' that serve as bridges that can help to transfer information from one group of social players to another. A similar argument is made by Burt (1992a,b) where 'structural holes' within networks are overarched by bridge ties with as little redundancy as possible. According to this approach building networks with many indirect ties is an effective way for a firm to reap the benefits of a large network without incurring the costs of maintaining a large number of direct ties. However, the assumption implicitly made is that direct links can be substituted for indirect links. Ahuja (2000) argues that the possibility to do so may be limited if benefits of direct and indirect links differ in magnitude and content. He presents an empirical assessment of the effects of direct and indirect ties on a firm's ability to innovate: both types of links enhance the performance of a focal firm. However, he also finds that indirect ties contribute much less than direct links. Therefore, the merits of the two types of links are different.

To distinguish between these benefits it is useful to define know-how and information. According to Ahuja (2000, p. 428) "Know-how entails accumulated skills and expertise in some activity and is likely to include a significant tacit and non-codifiable dimension. Information refers primarily to facts, discrete quanta of information that can be transmitted through simple communication in relatively complete form and without loss of integrity". Direct links provide access to both know-how and information available at the partner firm. However, bridge ties can provide access only to information (knowledge spill-over) concerning knowledge available at the indirect link. In line with this Gulati and Garguilo (1999) observe that a firm's partners also bring the knowledge and experience from their collaboration with their partners to the focal firm. A firm's partners therefore provide it with access not only to the knowledge held by its partners but also to the knowledge of its partner's partners. Ahuja (2000) indicates that bridge ties may provide information for instance on the success or failure of many simultaneous research efforts at indirect links. This facilitates early detection of promising technological trajectories as well as technological dead-ends. Such information of developments at indirect links may help a focal firm to assess the future development of its own core technologies. However, information from an indirect tie does not enable knowledge sharing as with a direct link and hence provides a rather noisy signal of the knowledge available at the indirect link. Collaboration facilitates exchange of non-codifiable and tacit information, yielding a more thorough learning process compared with learning through information obtained concerning technological developments at indirect links. In this case a more accurate signal is obtained concerning the competences available at the direct link. 
In our model we consider three firms, and in order to facilitate the discussion, we label them A-C. At the moment at which firm A considers aligning with just $\mathrm{B}$ or with both $\mathrm{B}$ and $\mathrm{C}$, the observations $x_{\mathrm{B}}$ and $x_{\mathrm{C}}$ that may be provided by these two firms to firm A are both normally distributed with mean $T$ and variance $\sigma_{x}^{2} .{ }^{21}$ However, we assume that firms B and C are working together already when firm A considers them as potential candidates for an alliance. Due to the collaboration of firms B and C, these firms have adjusted their competences because of an exchange of know-how and information as defined above (cf. Ahuja, 2000). Hence, the signals they may give to firm A concerning $T$ incorporate the knowledge obtained from each other. To capture that their knowledge bases overlap to a certain extent, we assume the observations $x_{\mathrm{B}}$ and $x_{\mathrm{C}}$ are correlated. This aspect of the model reflects the notion that both firm $\mathrm{B}$ and $\mathrm{C}$ incorporate the knowledge obtained during their partnership in their own knowledge base and is captured by the covariance of $x_{\mathrm{B}}$ and $x_{\mathrm{C}}$ given by $\sigma_{\mathrm{BC}}$. The observations $x_{\mathrm{B}}$ and $x_{\mathrm{C}}$ may differ even though $\mathrm{B}$ and $\mathrm{C}$ have been working together for at least three reasons. First, both firm $\mathrm{B}$ and $\mathrm{C}$ may also develop new insights independent from each other, possibly by interacting with other firms not considered in our model. Second, it is not likely that both B and C have completely revealed their competences to each other for strategic reasons. Usually firms try to control the knowledge flow to their partner using, for instance, gatekeepers. Third, both B and $\mathrm{C}$ will also try to protect parts of their knowledge base and limit access by firm A. These arguments also imply that receiving $x_{\mathrm{B}}$ from cooperating with firm B does not render the observation of $x_{\mathrm{C}}$ or a signal of it completely superfluous. We like to note that our model does allow for the possibility that information obtained from firm $\mathrm{C}$ is redundant to some extent. The extent to which $x_{\mathrm{C}}$ or its signal that we discuss in the next paragraph (i.e., $z_{\mathrm{C}}$ ) are superfluous is measured by the covariance $\sigma_{\mathrm{BC}}$ in our model.

In line with Ahuja (2000) cooperating with B allows exchange of know-how and information concerning some of the competences available at firm B. Hence, firm A obtains observation $x_{\mathrm{B}}$. Forming an alliance with firm $\mathrm{C}$ yields observation $x_{\mathrm{C}}$, reflecting exchange of know-how and information as well. However, if firm A cooperates only with firm B, then exchange of knowhow with firm $\mathrm{C}$ is impossible. Only some information on promising technological research projects or failures at firm $\mathrm{C}$ will be obtained by allying with firm $\mathrm{B}$ since firm $\mathrm{C}$ is a direct link of firm B and thus an indirect tie of firm A. Therefore the alliance with firm B yields a signal $z_{\mathrm{C}}$ of observation $x_{\mathrm{C}}$. It is less precise than $x_{\mathrm{C}}$ because the exchange of know-how with firm $\mathrm{C}$ is absent now, which prohibits a thorough learning process concerning the competences residing in firm $\mathrm{C}$. The value or quality of observation $x_{\mathrm{C}}$ will decrease since it is transmitted through an indirect link (cf. Jackson and Wolinsky, 1996; Bala and Goyal, 2000). To take account of such decay we assume that $x_{\mathrm{C}}$ will be observed by firm A with an error. Hence, firm A receives a signal $z_{\mathrm{C}}=x_{\mathrm{C}}+\eta$ where $\eta$ is a transmission error that is normally distributed with zero mean and variance $\sigma_{\eta}^{2}$ and that is not correlated with either $x_{\mathrm{B}}$ or $x_{\mathrm{C}}$. Hence, signal $z_{\mathrm{C}}$ is normally distributed with mean $T$ and variance $\sigma_{x}^{2}+\sigma_{\eta}^{2}$. The covariance between $x_{\mathrm{B}}$ and $z_{\mathrm{C}}$ is equal to $\sigma_{\mathrm{BC}}$.

Suppose now that firm A considers the two following strategies. The first strategy involves the formation of an alliance with firm B but not with firm C. We assumed that firm B has already established an alliance with firm C. As a consequence, a signal $z_{\mathrm{C}}$ of $x_{\mathrm{C}}$ is obtained as well by firm $\mathrm{A}$ if it allies with firm B. As a result, by incurring only cost $c$ the firm obtains two observations:

\footnotetext{
${ }^{21}$ Because of symmetry we could also investigate the situation where firm A considers the choice between aligning with $\mathrm{C}$, and aligning with both $\mathrm{B}$ and $\mathrm{C}$, without affecting any of our conclusions below.
} 
$x_{\mathrm{B}}$ and $z_{\mathrm{C}}$. The covariance matrix of these variables is given by

$$
\Sigma_{x z}=\left(\begin{array}{ll}
\sigma_{x}^{2} & \sigma_{\mathrm{BC}} \\
\sigma_{\mathrm{BC}} & \sigma_{x}^{2}+\sigma_{\eta}^{2}
\end{array}\right) .
$$

It is straightforward to show within the present model that alliances also yielding indirect ties are preferred to those that do not yield any indirect ties at all if no additional costs occur. In terms of network analysis this implies that a company searches for alliances with other firms that are also well connected to their own specific networks. As a consequence, a partner company should ideally be characterized by both a high network centrality and a high betweenness centrality. This network centrality refers to the number of direct links of a particular company with other companies. In an information-network the possibility to control the flow of information between other companies is also dependent on a company's degree of betweenness centrality. This refers to the number of times a company is located on the shortest geodesic path between other companies (Freeman, 1979; Hagedoorn and Duysters, 2002; Knoke and Kuklinski, 1982).

The second strategy the firm may pursue is to form direct alliances with both firms B and C. The advantage of this strategy is that in this case both $x_{\mathrm{B}}$ and $x_{\mathrm{C}}$ are observed without any error, but the costs are $2 c$. The properties of these observations are the same as before. The covariance matrix of $x_{\mathrm{B}}$ and $x_{\mathrm{C}}$ is given by

$$
\Sigma_{x x}=\left(\begin{array}{cc}
\sigma_{x}^{2} & \sigma_{\mathrm{BC}} \\
\sigma_{\mathrm{BC}} & \sigma_{x}^{2}
\end{array}\right)
$$

The cost of observing $x_{\mathrm{B}}$ and $x_{\mathrm{C}}$ equals $2 c$. The first strategy is preferred to the second one if ${ }^{22}$

$$
a \sqrt{\frac{2}{\pi}\left(\frac{1}{\sigma_{T}^{2}}+\frac{2 \sigma_{x}^{2}+\sigma_{\eta}^{2}-2 \sigma_{\mathrm{BC}}}{\sigma_{x}^{4}+\sigma_{x}^{2} \sigma_{\eta}^{2}-\sigma_{\mathrm{BC}}^{2}}\right)^{-1}}-a \sqrt{\frac{2}{\pi}\left(\frac{1}{\sigma_{T}^{2}}+\frac{2 \sigma_{x}^{2}-2 \sigma_{\mathrm{BC}}}{\sigma_{x}^{4}-\sigma_{\mathrm{BC}}^{2}}\right)^{-1}}-c<0 .
$$

It is straightforward to show that the left hand side of this expression increases with a higher degree of initial uncertainty (i.e., $\sigma_{T}^{2}$ ) and increases with a higher degree of transmission ambiguity (i.e., $\sigma_{\eta}^{2}$ ). These properties lead to our third proposition.

\section{Proposition 3. Direct ties are preferred to indirect ties if}

- the cost of forming alliances (i.e., c) is low,

- the cost of making mistakes as measured by a is high,

- if uncertainty as measured by $\sigma_{T}^{2}$ is high,

- the degree of transmission ambiguity as measured by $\sigma_{\eta}^{2}$ is high.

This implies that with increasing uncertainty a company will expand its number of direct links to a variety of other companies to improve the accuracy of communication between the ties, leading to dense networks. This result contradicts the efficiency approach within current social network theory, which states that under these conditions companies should aim at establishing efficient networks by means of a limited number of ties that act as bridges

\footnotetext{
22 See the appendix.
} 
to other indirectly connected companies (Burt, 1992a; Rowley et al., 2000). However, our result is more in line with the 'closure' argument of Coleman who states that information rich dense networks of direct ties are more beneficial to network-actors than sparse networks. An illustration of this phenomenon is found in the biotechnology sector, which is characterised by a high degree of uncertainty. Many pharmaceutical and biotechnology companies establish a dense and partly overlapping network with a multitude of well-connected partners that enables them to learn about interesting opportunities from a wide variety of sources (see Powell et al., 1996; Walker et al., 1997). In more mature and technologically less turbulent industries such as in heavy electrical equipment, basic chemicals, and food and beverages, we find fewer alliances, and inter-firm industry networks are characterized by lower density than found in sectors such as biotechnology and the more advanced sub-sectors of the information technology industry. In industries with less technological uncertainty, there are fewer multiple alliances between partners over time, and the network is relatively sparse as companies engage in only a limited number of alliances aimed at gaining access to new information (Hagedoorn, 1995). Consequently, as the networks in these industries are thin and with fewer direct ties, the relative importance of indirect ties between companies increases (see also Walker et al., 1997). Our model explains this fact by revealing that in these examples where technological uncertainty is low, the incentive to transform an indirect tie into a direct one is very low.

\section{Conclusion}

We employ a Bayesian learning model in which a firm obtains information about the desired future technology by forming alliances with other firms. We find that the number of firms a company will ally with increases with the degree of uncertainty it faces (cf. Mody, 1993). In classical social network theory this growth in interaction is referred to as 'gregariousness' (Erbe, 1962). However, we also argue that the incentive to form alliances decreases once the information of possible partners has become somewhat similar. In fact, we find that a firm is less likely to form many alliances if these different alliances share a common knowledge base. Such alliances have a higher degree of redundancy. This finding is in line with arguments advanced by Burt (1992a,b), who argues that the number of non-redundant contacts matters. Furthermore, our paper indicates that under higher uncertainty, redundant contacts become less attractive partners. If the information these contacts yield is very similar, even if such alliances are less costly to form, a firm will prefer non-redundant ties. Members of networks to which the firm has no ties yet and possess non-redundant information become appealing partners. Standard social network theory predicts that companies should establish efficient networks characterised by a limited number of contacts that form ties to other indirectly connected companies. However, our model indicates that with higher uncertainty, direct contacts, yielding more accurate information than indirect ties, become more attractive. This ultimately leads to dense networks.

Our model employs a number of specific assumptions. Hence, several extensions of the analysis are worth investigating, but they are beyond the scope of the present paper. First, our model discusses the optimisation problem from the point of view of a single firm. A next step is to extend our model to account for the fact that stable links require approval of all participants involved (cf. Jackson and Wolinsky, 1996). Second, we assume key parameters to be given and known to the management of the firm. This can be replaced by an assumption that the uncertainty regarding these parameters can be represented by some prior probability density function. 
Third, in Section 1 we assume that information obtained from alliances is similar. This degree of similarity is determined exogenously. An extension of the model could account for endogeneity, different technologies and strategic (learning) behaviour of companies. Such an extended model could use other functional forms for the objective function, for instance by allowing for increasing costs of managing a network, and it could include other motives than collecting information for network formation (e.g. joint projects). Fourth, we assume that firms learn about one single technology as given by a variable $T$. The model can be easily extended to allow for learning about various aspects of technology and other matters of interest to the firm, by assuming $T$ and $x$ (i.e., the observation on the technology) to be vectors of values. A formal analysis of such extensions can be found in Raiffa and Schlaifer (1961) or in Zellner (1971). Fifth, one could allow for heterogeneity among potential participants in an alliance. For instance, if the most valued information provider is a rival firm, which has the lowest incentive to share its information, the costs of forming an alliance will be high. This case could be dealt with by differentiating the cost structure on the basis of prior expectations about the value of the information obtained.

It is also interesting to extend our line of modelling into some empirical models, testing major elements of the above in alternative empirical settings such as industries characterised by different levels of technological development. In that context the use of a combination of existing network indicators, derived from current social network analysis, and the development of new network measures seems both appropriate and necessary to expand this line of work further.

\section{Acknowledgements}

The authors thank Geert Duysters, their discussants Reinhilde Veugelers and Pierre Mohnen, other workshop participants and two anonymous referees of this journal for their helpful and stimulating comments.

\section{Appendix A. Supplementary data}

Supplementary data associated with this article can be found, in the online version, at doi:10.1016/j.jebo.2006.05.003.

\section{References}

Ahuja, G., 2000. Collaboration networks, structural holes, and innovation: a longitudinal study. Administrative Science Quarterly 45, 425-455.

Arora, A., 1995. Licensing tacit knowledge: intellectual property rights and the market of know-how. Economics of Innovation and Technology 4, 41-59.

Arora, A., Gambardella, A., 1994. Evaluating technological information and utilizing it. Journal of Economic Behavior and Organization 24, 92-114.

Bala, V., Goyal, S., 2000. A noncooperative model of network formation. Econometrica 68, 1181-1229.

Barney, J., 1991. Firm resources and sustained competitive advantage. Journal of Management 17, 99-120.

Barney, J., 2001. Resource-based theories of competitive advantage: a ten-year retrospective on the resource-based view. Journal of Management 27, 643-650.

Burt, R.S., 1992a. Structural Holes-The Social Structure of Competition. Harvard University Press, Cambridge, MA.

Burt, R.S., 1992b. The social structure of competition. In: Nohria, N., Eccles, R.G. (Eds.), Networks and Organizations. Harvard Business School Press, Boston, MA, pp. 57-91.

Cohen, W.M., Levinthal, D.A., 1990. Absorptive capacity: a new perspective on learning and innovation. Administrative Science Quarterly 35, 128-152. 
Coleman, J.S., 1988. Social capital in the creation of human capital. American Journal of Sociology 94, 95-120.

Cukierman, A., 1980. The effects of uncertainty on investment under risk neutrality with endogenous information. Journal of Political Economy 88, 462-475.

DeGroot, M.H., 1970. Optimal Statistical Decisions. McGraw-Hill, New York.

Dosi, G., 1982. Technological paradigms and technological trajectories. Research Policy 11, 147-162.

Eisenhardt, K.M., Schoonhoven, C.B., 1996. Resource-based view of strategic alliance formation: strategic and social effects in entrepreneurial firms. Organization Science 7, 136-150.

Erbe, W., 1962. Gregariousness, group membership, and the flow of information. American Journal of Sociology 67, 502-516.

Freeman, L.C., 1979. Centrality in social networks. Social Networks 1, 215-239.

Gomes-Casseres, B., 1996. The Alliance Revolution-The New Shape of Business Rivalry. Harvard University Press, Cambridge, MA.

Granovetter, M.S., 1973. The strength of weak ties. American Journal of Sociology 78, 1360-1380.

Gulati, R., 1995a. Does familiarity breed trust? The implications of repeated ties for contractual choice in alliances. Academy of Management Journal 38, 85-112.

Gulati, R., 1995b. Social structure and alliance formation patterns: a longitudinal analysis. Administrative Science Quarterly 40, 619-652.

Gulati, R., Garguilo, M., 1999. Where do interorganizational networks come from? American Journal of Sociology 104 , 1439-1493.

Hagedoorn, J., 1995. Strategic technology partnering during the eighties: trends, networks and corporate patterns in non-core technologies. Research Policy 24, 207-231.

Hagedoorn, J., Duysters, G., 2002. Learning in dynamic inter-firm networks-the efficacy of multiple contacts. Organization Studies 23, 525-548.

Howells, J., 1996. Tacit knowledge, innovation and technology transfer. Technology Analysis and Strategic Management 8, 91-106.

Jackson, M.O., Wolinsky, A., 1996. A strategic model of social and economic networks. Journal of Economic Theory 71 , 44-74.

Knoke, D., Kuklinski, J.H., 1982. Network Analysis. Sage Publications, London.

Lorrain, F., White, H.C., 1971. Structural equivalence of individuals in social networks. Journal of Mathematical Sociology $1,49-80$.

Madhok, A., Tallman, S.B., 1998. Resources, transactions and rents: managing value through interfirm collaborative relationships. Organization Science 9, 326-339.

Mody, A., 1993. Learning through alliances. Journal of Economic Behaviour and Organization 20, 151-170.

Nelson, R.R., Winter, S.G., 1977. In search of useful theory of innovation. Research Policy 6, 36-75.

Nooteboom, B., Berger, H., Noorderhaven, N.G., 1997. Effects of trust and governance on relational risk. Academy of Management Journal 40, 308-338.

Poppo, L., Zenger, T., 2002. Do formal contracts and relational governance function as substitutes or complements? Strategic Management Journal 23, 707-725.

Powell, W., Koput, K., Smith-Doerr, L., 1996. Inter-organizational collaboration and the locus of innovation: networks of learning in biotechnology. Administrative Science Quarterly 41, 116-145.

Raiffa, H., Schlaifer, R., 1961. Applied Statistical Decision Theory. MIT Press, Cambridge, MA.

Ring, P.S., 2002. The role of contract in strategic alliances. In: Contractor, F.J., Lorange, P. (Eds.), Cooperative Strategies and Alliances. Pergamon, Amsterdam, pp. 145-162.

Roijakkers, N., Hagedoorn, J., van Kranenburg, H., 2005. Dual market structures and the likelihood of repeated ties-evidence from pharmaceutical biotechnology. Research Policy 34, 235-245.

Roijakkers, N., Hagedoorn, J., 2006. Inter-firm R\&D partnering in pharmaceutical biotechnology since 1975: trends, patterns, and networks. Research Policy 35, 431-446.

Rothaermel, F.T., 2001. Incumbent's advantage through exploiting complementary assets via interfirm cooperation. Strategic Management Journal 22, 687-699.

Rothaermel, F.T., Deeds, D.L., 2004. Exploration and exploitation alliances in biotechnology: a system of new product development. Strategic Management Journal 25, 201-221.

Rowley, T., Behrens, D., Krackhardt, D., 2000. Redundant governance structures: an analysis of structural and relational embeddedness in the steel and semiconductor industries. Strategic Management Journal 21, 369386.

Saxton, T., 1997. The effects of partner and relationship characteristics on alliance outcomes. Academy of Management Journal 40, 483-498. 
Uzzi, B., 1997. Social structure and competition in interfirm networks: the paradox of embeddedness. Administrative Science Quarterly 42, 35-67.

Walker, G., Kogut, B., Shan, W., 1997. Social capital, structural holes and the formation of an industry network. Organization Science 8, 109-125.

Zellner, A., 1971. An Introduction to Bayesian Inference in Econometrics. John Wiley and Sons, Chichester.

\section{Further reading}

Baltagi, B.H., 1995. Econometric Analysis of Panel Data. John Wiley \& Sons, New York. 